\title{
Software Quality Management and Software Process Improvement in Denmark
}

\author{
Kautz, Karlheinz; Ramzan, Faisal
}

Document Version

Final published version

Published in:

Proceedings of the 34th Annual Hawaii International Conference on System Sciences. HICSS-34

Publication date:

2001

License

Unspecified

Citation for published version (APA):

Kautz, K., \& Ramzan, F. (2001). Software Quality Management and Software Process Improvement in Denmark. In R. H. Sprague, Jr. (Ed.), Proceedings of the 34th Annual Hawaii International Conference on System Sciences. HICSS-34 IEEE.

Link to publication in CBS Research Portal

\section{General rights}

Copyright and moral rights for the publications made accessible in the public portal are retained by the authors and/or other copyright owners and it is a condition of accessing publications that users recognise and abide by the legal requirements associated with these rights.

\section{Take down policy}

If you believe that this document breaches copyright please contact us (research.lib@cbs.dk) providing details, and we will remove access to the work immediately and investigate your claim.

Download date: 26. Apr. 2023
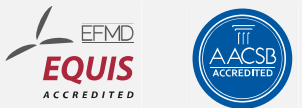


\title{
Software Quality Management and Software Process Improvement in Denmark
}

\author{
Karlheinz Kautz \& Faisal Ramzan \\ Copenhagen Business School, Department of Informatics, Denmark \\ Karl.Kautz@cbs.dk, faisal.ramzan@dk.arthurandersen.com
}

\begin{abstract}
The software business is a fast growing industry sector and lack of quality has a significant consequence for society and economy. However, reports about unfinished development projects, project overruns and system and software failures are still the rule. Software quality management (SQM) standards and software process improvement (SPI) methodologies are all promoted to solve these problems. However, little is known about how prevalent these standards and methodologies actually are. We have, therefore, performed a questionnaire-based survey in the Danish software producing industry. The standards and methodologies are not known by $40 \%$ of the responding organizations. Only $36 \%$ of the enterprises use one or several of the approaches to some degree, while two thirds of the organizations that had not adopted any of the approaches had never heard about them. These and additional results about the use of standards and the problems with introducing standards will be presented and discussed in detail in the paper.
\end{abstract}

\section{Introduction}

Software development is a complex process that covers various activities until the final product has been completed. Many organizations have problems and project overruns and defective systems are still the rule.

We might share the opinion of the Danish Minister of Labour, who recently commented on the scandal ${ }^{1}$ with implementing the Danish Employment Service system Amanda. He saw no reason for unease as defective functionality and budget overruns are an inherent element of software production ([1]).

But perhaps we should be concerned as software plays a more and more important role in private and professional

\footnotetext{
${ }^{1}$ According to Politiken, one of Denmark's largest daily newspapers, 18.05.2000, the project had a schedule overrun of over $60 \%$ and a budget overrun of more than $70 \%$ (approx. 23 mill. \$).
}

life. According to Zahran ([2]), approx. 4000 people have lost their lives due to software errors in recent years, and within the emerging area of e-commerce, a mistake in an electronic payment system may have fatal consequences for organizations that invest in such technology.

Instead of ignoring such problems, software producing companies ought to make an effort to understand the difficulties and how they can solve them.

After numerous attempts to improve the situation through technical approaches ranging from structured programming over CASE tools to object orientation, managerial approaches based on the insight that a product can only be as good as its development process are gaining ground. These approaches are generally known as software quality management (SQM) standards and/or software process improvement (SPI) [3].

In Denmark, there have only been a few studies about how selected organizations have employed the approaches. However, to ensure a further propagation of the measures, it is essential to determine how well known the approaches are, the extent of their application, the specific reasons for their adoption or non-adoption and their perceived effects. This is the objective of the study reported in this paper.

The paper is organized as follows. The next section will outline the research framework. Then, the results will be organized in sections covering demographic data, awareness and utilization of SQM and SPI, SQM and SPI and the perception of software development problems, introduction of SQM and SPI, and objectives and effects of SQM and SPI. Finally, the main conclusions of the study will be compared with similar work and further research questions will be suggested.

\section{Research Framework}

\section{Contents of the Study}

The study, which was performed in 1999, deals with knowledge and utilization of SQM standards and SPI methodologies. It covers the ISO9001 standard [6] for quality management systems, its guidelines for implementation in software organizations and the specially developed TickIT scheme [7,]. The latter gives even more precise details about the realization of these 
standards based on an initiative of the British Computer Society and British Standards Institution.

In addition, the staged capability maturity model (CMM) [8] developed at the Software Engineering Institute (SEI) in the USA and its European counterpart BOOTSTRAP [9], which is based on the ISO-standards and the CMM, are covered by the study. We were also interested in the diffusion of SPICE [10], a standard for software process assessment and improvement methodologies. The respondents in the survey could also suggest alternative wide-ranging as well as self-developed methodologies that they used in comprehensive quality management and software process improvement.

Finally, we also asked about the use of individual improvement measures such as evaluation and amendment of planning, tracking, control and review activities, single quality assurance techniques like structured walk-throughs of specification documents, unit, integration and validation testing as opposed to or as part of the above named all-inclusive standard and process improvement methodologies.

The study does not involve metrics-driven approaches (see f. ex. [11], [12]). They are not based on formal audits and/or assessments of the current practice and problems and do not include an explicit model for improvement. As such, they are different from standards and modelbased approaches. Therefore, they will not be considered here although they might be valuable supplements for software quality management and software process improvement.

\section{Research Method}

To answer the research questions, a survey instrument with 64 questions was developed and tested in three cycles with representatives from the target population. Both nominal and ordinal scale variables were applied, and where it was necessary groupings of answer categories were made. The data was statistically evaluated, and to secure the significance of the results three tests - a chi-square, a likelihood ratio chi-square, and a $\mathrm{MH}$ chi-square test - were performed and a significance level of 0,05 was chosen [13].

The questionnaire was sent to 580 organizations, either to the managing director, the IT manager or the quality manager, where they were known. The 80 member companies of the Danish Computer Technology Forum all received a questionnaire. The remaining 500 companies were chosen from two databases for organizations that employ software developers or provide software consultation. From a composed list of 1100 organizations with a limited number of enterprises with fewer than 5-10 employees - these had originally been the largest portion of the approx. 8000 registered firms 500 were randomly chosen. 33 organizations declined to take part in the study, and out of the 118 responses 7 could not be used. With 111 usable answers, we achieved a response rate of $20,3 \%$, which is quite satisfying.

The responses fell into two categories, namely companies that consider software as their primary product and companies that develop software as part of their primary product or service. In representing the results, we will relate to this distinction, wherever it is significant.

The population can also be divided into the group that uses the standards and/or improvement approaches and the group that does not. To examine the reasons for adoption and non-adoption, the survey respondents were asked whether they were willing to participate in an interview study. As a result, we interviewed six individual representatives from six companies on the basis of an open, theme-oriented interview guide. Three of the companies used quality management and/or process improvement and three did not apply any of the approaches. Each interview lasted 90 minutes and was verified by the interviewed person. The results have not been used to generalize issues, but to support some of the correlations that the survey only can touch on the surface. The method triangulation met the requirements of representativity, validity, and reliability, which must be set in a descriptive and explanatory investigation like ours [14].

\section{Demographic Data}

\section{Industry Sector}

As stated, 111 organizations participated in the survey: $72 \%$ (81) consider themselves to be part of the IT sector, $13 \%$ are from industry, $6 \%$ from banking and finance, $4 \%$ from telecommunication and $5 \%$ from unspecified other sectors.

\section{Size and Product Portfolio}

The majority (67\%) has more than 50 employees. However, in the IT sector 42 organizations have fewer than 50 staff members, whereas this only applies to two of the other organizations. As the response rate of organizations with fewer than 25 employees is quite low, some of the conclusions where size is an issue must be considered with some reservations.

In the IT sector, $80 \%$ of the companies have a software development department, whereas the number is $97 \%$ for other companies. In terms of size of software development projects and project groups, $66 \%$ of all the companies report that their projects are under 3 manyears. In the IT sector, it is $73 \%$ and in the rest of the companies, it is $47 \%$. The project groups have 1-5 members in $55 \%$ of the cases (61) and 6-20 members in $38 \%$ (43). Only $6 \%$ of the organizations have projects 
that include more than 21 project members. In the IT sector, $61 \%$ (50) have project groups with 1-5 members, in the other sectors the percentage is 37 (11).

Of the non-IT organizations, 33\% (13) make standard products for the market, $28 \%$ (11) make tailor-made customer products and the same number of organizations work with development for internal company purposes. The IT sector is dominated by adjustment of standard products $(38 \%)$ and the development of tailor-made customer systems $(35 \%)$.

The data shows that large organizations regardless of which sector they belong to have large development departments. Larger enterprises have larger projects in terms of staff and man-years. A possible explanation of the differences can be found in the interviews. They show that non-IT organizations have larger projects comprising more man-years. When a product is finished, it has to be maintained and developed further, which seems to take place in the same project rather than in a new development project.

The results also show that large organizations more frequently engage in development for internal purposes.

\section{Respondents' Profiles}

The respondents are experienced staff members: $83 \%$ are older than 36, 56\% have been employed longer than 6 years in the company, $69 \%$ have been in their actual position longer than 3 years, $83 \%$ have over 6 years of experience with software development and $51 \%$ have performed more than 20 development projects. With reference to quality management, $57 \%$ have 3 or more years of experience, $35 \%$ (39) are managing directors. In the IT sector, the percentage is 46 (37) and for the rest of the organizations $7 \%$ (2).

Also other results on the differences between respondents from the IT sector and the rest of the organizations are interesting. In terms of performed development projects, $60 \%$ (48) in the IT sector have performed more than 20 development projects. For the rest of the organizations, the number is only $28 \%$ (8). This might be linked to the size of the projects, which is smaller and shorter in the IT sector. The assumption is confirmed by the figures showing development experience expressed in years: $77 \%$ (23) of the respondents from non-IT organizations have over 11 years of development experience in contrast to $47 \%$ (38) in the IT sector. In terms of age and experience with quality management, $44 \%$ (35) of the respondents from IT companies are over 41 years old. For the rest of the organizations, the number is $67 \%$ (20) and more than $50 \%$ (15) of the respondents in this segment have more than 6 years of experience with quality management. For the IT sector, the percentage is 26 (21). A possible explanation of these figures might be that nonIT organizations have dealt with quality management for a longer period of time (and) in other situations than their software departments.

\section{Knowing and Using Software Quality Management and Software Process Improvement}

\section{Knowledge about SQM/SPI}

Knowledge about SQM and SPI is a prerequisite for utilizing them. However, 40\% (44) of the organizations do not know either the ISO9001 standard, the TickIT scheme, the CMM, Bootstrap or SPICE. For the IT-sector, the figure is $51 \%$ (41), for the rest of the organizations $10 \%$ (3). All others know at least one methodology.

In terms of single methodologies, the CMM is best known: 52\% know CMM, 40\% know Bootstrap, 34\% know the TickIT/ISO scheme and 26\% know SPICE. The study also shows - although not statistically supported that organizations which use one methodology also know about others. Out of the 40 organizations that use SQM/SPI, 30 know the CMM, 23 the TickIT scheme, 22 Bootstrap and 17 SPICE. For the 70 organizations without SQM/SPI, the numbers are lower: 28 know the CMM, 22 Bootstrap, 15 the TickIT scheme and 12 SPICE. This indicates that the organizations base their decision to introduce a particular SQM/SPI methodology on a conscious evaluation process and knowledge about alternative approaches.

However, there is a clear need for more information in Danish IT producing organizations: $71 \%$ explain their ignorance with a lack of information, whereas only $11 \%$ have no interest in SQM/SPI and 9\% find it irrelevant.

\section{Utilization of SQM/SPI}

There exists an overwhelmingly positive attitude towards SQM/SPI methods ${ }^{2}$, which is expressed by $87 \%$ of the general managers, $86 \%$ of the IT managers and $73 \%$ of all staff members. This is probably due to the positive connotation of the concept quality.

However, 64\% (71) of the responding organizations are not using SQM/SPI. As reasons they state that SQM/SPI is too resource demanding (25\%), that their staff lacks training and education in the area (24) and that they lack information $(21 \%)$. 30\% have not at all considered $\mathrm{SQM} / \mathrm{SPI}$ and $8 \%$ think it is irrelevant for them. However, $8 \%$ are planning to adopt it and $54 \%$ are considering the issue because they want to identify the weaknesses of their processes (32\%), they experience too many mistakes $(25 \%)$ or they have a request from management $(20 \%)$.

\footnotetext{
2 The numbers are even higher for the utilisation of software development methodologies and tools, but this will not be discussed here.
} 
In terms of single improvement techniques, one or more of them are used by $89 \%$ of the organizations. Standalone quality assurance in the form of testing is applied by $93 \%$ of all organizations, structured walk-throughs by $78 \%$ and monitoring of functionality (acceptance test) by $71 \%$. There are no significant differences in the use of these techniques by the different sectors or in the other characteristics of organizations with and without SQM/SPI.

The study also shows that $36 \%$ (40) of the responding organizations use SQM and/or SPI: $24 \%$ are ISO certified, 22\% use Bootstrap, $18 \%$ use CMM, $14 \%$ use a methodology they have developed themselves, $14 \%$ name methodologies that we had not inquired about ${ }^{3}, 6 \%$ are TickIT certified and $2 \%$ use the TickIT scheme, but without certification and nine organizations use more than one approach.

On a first glance, these figures give the impression that SQM/SPI is already widely used in Denmark. However, looking at the IT sector and the other organizations separately reveals that

- in the IT-sector, only $28 \%$ (23) of the organizations use SQM/SPI, whereas $72 \%$ (58) do not; 23 organizations use methodologies that fall into the category 'other', $8 \%$ use self-developed approaches, $19 \%$ are ISO certified, $19 \%$ use the CMM and $15 \%$ use Bootstrap; $4 \%$ use more than one approach

- in the rest of the organizations, $32 \%$ (8) are ISO certified, $28 \%$ (7) use Bootstrap, 20\% (5) have their own developed methodology, $18 \%$ (4) use the CMM and $4 \%$ (1) use something else; $20 \%$ (6) use more than one approach.

Given the fact that it is an extensive and resource demanding endeavor to deploy the standards and methodologies completely, two explanations present themselves: SQM/SPI is really widespread in Denmark, or not all organizations apply the approaches in the formally pre- and described way. The interview results support the second explanation: Organizations adjust SQM and SPI standards and methodologies to their own needs instead of applying them completely as described in the literature. Therefore, the number of organizations that apply the methodologies fully is almost certainly lower than 40 .

\section{Characteristics of Organizations with SQM/SPI}

There is a greater tendency that large organizations and large software development projects, measured in manyear, will utilize SQM/SPI. The size of the development department or the project groups does not seem to be an issue.

\footnotetext{
${ }^{3}$ We did not investigate the features of these methodologies.
}

The reason might be that larger organizations have more resources and therefore better possibilities for engaging in SQM/SPI. However, this does not mean that SQM/SPI is only used by such enterprises. As a matter of fact, $61 \%$ (14) of the organizations in the IT sector with less than 100 employees use SQM/SPI and 30\% (7) of the organizations within this category have under 50 staff members. Thus, SQM/SPI also appears to be suitable for smaller organizations.

The IT sector has less experience with SQM and/or SPI than the rest of the organizations: over $50 \%$ (14) of the organizations in the IT sector have under 4 years of experience. The percentage for the other organizations is 25 (4). Over $50 \%$ (8) of the non-IT organizations have more than 8 years of experience in the area. In the IT sector, the percentage is only 22 (5). This is probably due to the long history of quality management that many nonIT organizations have with regard to production of their primary product.

$77 \%$ of the non-IT and $57 \%$ of the IT organizations have their own quality departments, and they are larger in the non-IT sector. This is probably because the quality department also deals with quality management of the primary product or service.

Focusing on a defined development process, $90 \%$ of the organizations using SQM/SPI answer that they have a defined process. For the organizations without SQM/SPI, the percentage is 39 .

\section{Software Quality Management, Software Process Improvement and the Perception of Problems}

\section{Problems with Software Development}

Software quality management and software process improvement are intended to solve the problems within software development. Therefore, we were interested in the respondents' general perception of problems in software development and their view of the relationship between the problems and SQM/SPI. In particular, we looked at the following technical and support activities: requirements analysis and specification, system design, programming, testing, documentation, project management, utilization of development standards, configuration management, quality assurance and change management (adjustment of project plans due to changed customer requirements). The most significant results are:

- requirements specification and change management are two areas that clearly stand apart from the others: $25 \%$ (28), respectively $24 \%$ (26) of all respondents consider these areas very problematic.

- requirements specification, testing, documentation, project management, quality assurance and change management are areas that more than $50 \%$ of the 
respondents regard as problematic or even very problematic.

- $68 \%$ (75) believe that programming creates little or no problems.

- $57 \%$ (63), $52 \% \quad(57)$ and $51 \%$ (56) look at development standards, systems design and configuration management as activities with no or almost no problems.

In general, the non-IT organizations look at the majority of the activities as more problematic than the IT sector does.

There is also a clear dependence between the perception of problems in the various areas. Organizations that regard requirements specification and systems as problematic also tend to see all other areas as problematic. There are also dependencies between other activities except for one or two areas.

\section{Size and Problem Perception}

In the context of quality management and process improvement, size is often used as a variable to explain adoption and non-adoption. If we take the perception of problems, large organizations tend to experience requirements specification, testing, documentation and configuration management as more problematic than small organizations do. In the IT sector, large organizations regard especially requirements specification as more problematic than small organizations do, and large project groups tend to view change management as more problematic than small project groups do. This seems very reasonable as large groups probably use more efforts to co-ordinate their work.

In summary, there is only little correlation between the organizations' sizes and their perception of problems, and there is no correlation between the size of software development departments, project groups and development and the respondents' perception of problems with software development.

\section{Using SQM/SPI and Problem Perception}

SQM standards and/or SPI approaches are used by $36 \%$ (40) of the organizations. These organizations believe that the activities within software development are more problematic than the organizations without such measures do. This applies in particular to requirements specification, system design, testing, documentation, project management and configuration management. There is a similar tendency for development standards and change management, but the connection is not statistically supported. The only area that more organizations with than without SQM/SPI consider almost without problems is quality assurance.
For the IT sector, the correlation is even stronger and shows that the difference between the enterprises that use quality management and those that do not is even bigger. We also asked the organizations whether they used standalone quality assurance measures and single improvement techniques: over $70 \%$ do so, but their utilization has no significance for the organizations' perception of problems within software development.

\section{SQM/SPI as Creators of Awareness}

There are at least three possible views of the differences in the perception of problems:

- Organizations that have introduced quality management have had substantial problems with software development, which is why they have started to deploy quality management and process improvement.

- Organizations that have not adopted SQM/SPI believe that they have no problems, and therefore they are not interested in the standards and approaches.

- Organizations that do not utilize quality and process measures have not realized that they have problems with software development, whereas organizations with SQM/SPI are more conscious of their problems within software development.

The last explanation seems most likely: 46 of the organizations without SQM/SPI are planing or considering to adopt these measures; 37 state they that are motivated to do so in order to identify the weaknesses in their development processes and because they see $\mathrm{SQM} / \mathrm{SPI}$ as an adequate approach.

The organizations regard SQM/SPI as an approach that can help them identify their problems and as such will give them an overview over their software development activities.

Our study shows that both organizations with and without SQM/SPI have problems with software development. Some of them do not even try to solve their problems, because they are simply not aware of them. Others are very conscious of how to work with such difficulties.

According to the majority of the respondents, SQM/SPI has an overall positive or very positive effect on all the different activities in software development, even when we take into account that organizations with SQM/SPI perceive software development as more problematic than organizations without such measures. This is in line with the third explanation.

Thus, SQM/SPI may provide an overview over the problems in software development and lead to a positive change in individual activities and the processes as a whole. 
We may argue that the positive effects actually confirm the first rationalization, but this is only part of the explanation. The interview results also support that organizations with SQM/SPI are more aware of their situation, because SQM/SPI gives them the opportunity via evaluations and assessments to focus on their actual status.

In comparison, organizations without SQM/SPI carry out their daily business without assessing and reflecting on the situation. They consider the existence of problems with requirements specification or project management as a natural element of software development.

It is not necessarily a formal assessment or an evaluation that is needed to become aware of the problems in software development, but the insight that performance can be improved is important. However, such an insight is often blocked by an understanding of quality management and process improvement as procedures that demand extensive documentation, are bureaucratic in nature and impede creativity. Another barrier might be that the business world just accepts that a majority of software projects overrun budgets and time schedules. Finally, as long as the staff is evaluated according to whether they deliver on time instead of whether they deliver quality, SQM and SPI will not be recognized as relevant. These attitudes must change before SQM/SPI can be seen as a relevant approach to improve process and product quality.

\section{Introducing Software Quality Management and Software Process Improvement}

\section{Initiating and Implementing SQM/SPI}

The main reasons why organizations start working with SQM/SPI are a fundamental interest in quality $(25 \%, 22)$, an awareness of too many mistakes $(22 \%, 19)$ and a demand from top management $(18 \%, 16)$. In over $70 \%$ of the cases, the initiative is taken by management - top management, software management or project management. In the IT sector, top management scored highest $(30 \%)$, perhaps owing to the short distance between management and development. In the rest of the organizations, the software managers $(44 \%)$ are the main initiators.

The study shows that $53 \%$ of the organizations use external assistance to introduce SQM/SPI. Primarily, the assistance is used for assessments and evaluations, launching and establishing a quality or improvement project and for consultation.

As a starting point, $50 \%$ of all organizations choose to implement SQM/SPI in selected projects, while 13\% start with selected departments, and $29 \%$ decide to start with a company wide implementation.
However, there is no correlation between the activities that are perceived as problematic and those on which the organizations start to apply SQM/SPI measures.

Project management, requirements specification, testing, development standards and system design are the areas on which improvements start. These areas are also where the measures of SQM/SPI have gained most ground and in fact been implemented.

The chosen implementation strategy - not to start on a company wide level - indicates that most organizations are aware of the complexity of the introduction process. This is confirmed by the respondents' answers, where $70 \%$ (28) grade the process as difficult or even very difficult.

\section{Problems of Implementing SQM/SPI}

During the introduction process, lack of resources (36\%), insufficient staff engagement (24\%), lack of engagement from project managers and lack of management support $(12 \%)$ are seen as the main problems. In terms of a solution, $16 \%$ suggest management support, while $34 \%$ mention training of staff and $25 \%$ call for training and education of project managers. As a consequence, 69\% provide training for their staff with regard to SQM/SPI ${ }^{4}$. In the IT sector, the percentage is 78 and in the other organizations it is 56. However, these organizations use more days on training than the IT sector. The difference between the IT sector and the rest of the organizations can be explained by the fact that only $41 \%$ of the non-IT organizations see training as a solution as opposed to $87 \%$ (20) in the IT sector. May be the staff in non-IT organizations already knows more about SQM/SPI due to the organizations' long deployment of SQM in non-IT departments.

\section{SQM/SPI and Organizational Change}

The implementation of SQM/SPI also leads to changes in the organizations in $63 \%$ (25) of the cases; the number is a little bit higher for the IT sector, where 65\% (15) of the organizations made changes as compared to $59 \%$ (10) of the other organizations. Thus, the introduction of SQM/SPI means organizational change.

The survey does not investigate which kind of changes take place, but the interviews show that the changes differ: some are changes of the physical and/or organizational structure, others are changes in the business and development processes.

They all have far reaching consequences on the organizations as a whole and are not considered as isolated solutions to local problems. As such, the

\footnotetext{
4 The number of staff members training in methodologies to support the technical activities is higher.
} 
introduction, implementation and utilization of SQM/SPI imply organizational development.

\section{Objectives and Impact of Software Quality Management and Software Process Improvement}

\section{Effects of SQM/SPI}

The study shows that the effect on the organizations' business variables based on a subjective judgement is perceived as positive or even very positive. This applies to customer satisfaction (79\%), staff satisfaction (73\%), delivery precision (62\%), staff motivation (52\%), resource consumption (50\%), cost reductions/expenses (43\%), and budgeting precision (36\%). Only in six cases are the effects judged as negative.

In terms of the technical and support activities for software development, the numbers are similar.

The respondents' answers indicate positive or very positive effects in the case of requirements specification (81\%), system design (53\%), programming (62\%), testing $(86 \%)$, documentation (69\%), project management $(75 \%)$, configuration management $(61 \%)$, use of development standards (55\%), quality assurance (70\%), and change management $(47 \%)$. Only in four cases were the effects negative.

The answers also indicate that a fourth of the organizations $(24 \%, 17)$ plan to expand into new processes. This shows that they are not only focusing on resources. They are interested in the new processes that SQM/SPI brings about. Still, 20\% (14) of the organizations intend to use more resources on SQM/SPI, and $27 \%$ (19) plan to introduce SQM/SPI thinking in the whole organization. 5

\section{Defining Aims and Measuring Achievements}

As mentioned, all the above figures are based on subjective assessment, and in the case of expenses, resource consumption, and budget precision nearly a third of the respondents are unable to make any statement at all about the effect. The same applies to the activities system design, utilization of development standards, quality assurance, and change management, although in this case only $1 / 5$ of the respondents are unable to give a statement. The study shows that all organizations with the exception of one have formulated business related objectives in at least one of the following areas: customer satisfaction (20\%), staff satisfaction (20\%), delivery precision (19\%),

\footnotetext{
5 The respective numbers for organizations without SQM/SPI are $35 \%$ (44) and 19\% (24).
}

staff motivation (8\%), resource consumption (9\%), cost reductions/expenses (13\%), and budgeting precision (9\%).

In total, $90 \%$ of the organizations using SQM state that they perform measurements, which are distributed as follows: $20 \%$ of all answers fall into the category of delivery precision, $18 \%$ measure customer satisfaction, $17 \%$ staff satisfaction, $14 \%$ expenses, $11 \%$ resource consumption, $10 \%$ budget precision and $9 \%$ staff motivation.

In terms of objectives for software development activities, 12 out of 40 organizations have not formulated any objectives, and only 23 organizations perform measurements. The actual distribution is: testing (objectives: 14\%, measurements: 14\%) documentation $(9 \%, 13 \%)$, system design $(7 \%, 7 \%)$, project management $(9 \%, 13 \%)$, programming $(8 \%, 7 \%)$, quality assurance $(12 \%, 12 \%)$, requirements specification $(12 \%, 12 \%)$, configuration management $(7 \%, 8 \%)$, development standards $10 \%, 8 \%)$, change management $(4 \%, 5 \%)$.

The study has not investigated which objectives the organizations have defined and how they perform the measurements. But it has not been possible to find any correlation between the organizations' defined objectives and their actual areas of measurement.

All this indicates that measurement in general is a very problematic area for all organizations, which is also confirmed by the interview results: none of the organizations has a functioning metrics program. However, this does not mean that organizations with SQM/SPI do not engage in measuring. They see it as a means to improve their processes, but have problems with defining the appropriate metrics, whereas organizations without SQM/SPI do not see the value of measurements.

\section{Summary}

The results of the study have to a certain extent already been discussed in the above sections. Here, we would like to summarize the results, place them in a context of related work and point out themes for future work. Almost all organizations have a positive attitude to
SQM, but SQM standards and/or SPI methodologies
are NOT known by $40 \%$ (44) organizations.
The positive attitude towards quality management is
probably related to the positive connotation of the concept
quality. However, knowledge about SQM/SPI is not very
widespread in Denmark. This is in line with the results
from a similar survey in Norway [15], whereas a survey
from 1995 [16] comparing Italy, the UK, Germany and
France shows that more than $75 \%$ of the respondents do 
not know SPI approaches and about $20 \%$ do not know the ISO9000 standard series.

\section{SQM and/or SPI are used by $36 \%$ (40) of the organizations.}

The study reports that $36 \%$ (40) of the organizations utilize SQM and/or SPI. We have already discussed that the actual number of organizations might be lower as most organizations have adjusted the standards and methodologies to their own needs or have developed their own approaches. In this light, a utilization rate of 56\% reported from Sweden[17] looks quite high. However, we do not know the definition of SQM underlying the survey. In Norway [15], 17\% use the TickIT/ISO scheme, whereas $8 \%$ use Bootstrap, the CMM or their own developed methodologies. In Sweden, the TickIT/ISO scheme and the CMM are most widespread, while SPICE is more common than BOOTSTRAP. In Denmark, ISO 9001, Bootstrap and the CMM are the most applied measures, whereas SPICE is not used at all. This difference is probably related to the fact that a particular Swedish change agency pushes the ISO standard and SPICE, whereas one agency in Denmark is very active promoting Bootstrap. The accumulated figures for Italy, the UK, Germany and France are: 33\% use the ISO9000 standard series for software activities, $28 \%$ use the CMM - in France the utilization is extensive (69\%), 8\% use SPICE - again, application in France is extensive (28\%), and $8 \%$ use Bootstrap.

\section{SQM and /or SPI increase awareness of software} development and its problems.

There is a widespread understanding that SQM and/or SPI increase the attention on software development processes (see f. ex. [9], [10], [18]). Methodologies, like the CMM, aim explicitly at providing a more sophisticated picture of the development activities in accordance with the organization's ascending level of maturity. Our study confirms that the awareness of software development grows with the use of SQM and/or SPI. In particular, our study concludes that organizations, which utilize SQM and/or SPI are more aware of their problems - and as such they have an appropriate basis for improvement - than organizations without SQM/SPI. A more recent European study [19] about problems in European software production units draws the same conclusion, but provides no evidence.

\section{SQM and /or SPI have a positive effect.}

In contrast to the conclusion [19] that SQM/SPI does not lead to a reduction of problems in software development, the respondents in our survey state that SQM/SPI have a very positive effect on both business and software development factors. This is in line with large parts of the literature (see f. ex. [2], [5], [8], [9], [20]). However, it must be borne in mind that the survey predominately has been answered by management, who in many cases are the initiators of the SQM and/or SPI endeavors. Furthermore, we have not required any assessment results and/or hard measurements as evidence for the respondents' subjective judgement.

SQM and/or SPI are used more by large organizations, but can be used successfully by organizations of all size.

The study shows that large organizations have a greater tendency to utilize SQM and/or SPI than smaller organizations. At the same time, our study indicates that both large and small organizations adjust the standards and the methodologies to their own needs. This is confirmed by f. ex. [5] and [21]. The study of the diffusion of SQM/SPI in Norway [15] provides results that also support our research. The Norwegian study concludes that larger organizations apply SQM/SPI to a greater extent than smaller ones. In fact, they argue that it is doubtful whether small companies will adopt methodologies like the CMM and Bootstrap, as these techniques seem to fit the needs of larger firms better. Originally, these methodologies were aimed at large organizations, [22], [23], [24] and [25], but SQM and/or SPI are also discussed in relation to small enterprises and attempts are made to show how these measures also can be used beneficially in smaller firms. The suitability of SQM and SPI for organizations of all sizes is corroborated by the fact that regardless of size most organizations report a positive effect of the measures.

Lack of resources and staff engagement are the biggest problems when introducing SQM and/or SPI.

Lack of resources is in general a problem when introducing novelties, especially in small and mediumsized organizations [26]. The Danish software producing units are no exception and confirm the results from the Norwegian study [15]. Lack of staff engagement might appear as a surprise, but as mentioned above the majority of the respondents are members of management. The survey does not inquire about the reasons for the staff's lack of engagement, but it might be a result of insufficient empowerment and encouragement to participate in the process. Active involvement, however, has long been recognized as one of the decisive factors for successful implementation of SQM and/or SPI programs [27].

Measurements and metric programs as part of SQM and/or SPI present a major problem.

Measurement is a complex process and the organizations in the study have major problems with metrics programs 
as a part of SQM and/or SPI. This is confirmed by the literature in the field (f. ex. [28], [29], [30], [31]). The literature contains some advice. However, it does not seem to be used very often. The Swedish study [17] substantiates this conclusion. It shows that measurements and metrics are seen as the most problematic factors compared to the other elements in SQM and SPI. The Swedish study also includes a European wide comparison, which also indicates that measurements are seen as the most problematic area of SQM and SPI.

\section{SQM and/or SPI imply organizational development.}

The conclusion of our study is underpinned by the literature, which confirms that SQM and/or SPI imply organizational development (see f. ex [2], [5], [8], [32]) that has consequences beyond the software producing units, i.e. it affects the organization as a whole. In our study, more than $50 \%$ of the answers state that they had performed structural changes in their organization when they introduced SQM and/or SPI. This insight might be well known and documented in other fields of management and in systems development (see f. ex, [33], [34]). However, when it comes to introducing the standards and methodologies involved in SQM and/or SPI in practice, the companies do not seem to be prepared to deal with the problems, which our study shows.

\section{Future Work}

This study was the first of its kind in Denmark and one of the few international studies in the area of diffusion and adoption of SQM/SPI. As such, it is a source of information for academics, practitioners and organizations that are engaged in or want to engage in SQM and/or SPI. The results are grounded in a solid statistical basis and method triangulation. However, during the design of the research we did not anticipate problems such as the relation between the respondents' positive attitude to quality and the comparable low deployment of quality management standards and improvement approaches, including the serious problems with measurements and metrics. Therefore, these issues have not been studied thoroughly. Here further in depth research is needed. The results of the study also raise a number of other unanswered questions. We will briefly present four of the questions that should be subject to further research:

- Small organizations do not seem to utilize SQM/SPI as regularly as large organizations. It would be interesting to investigate more thoroughly why this is so.

- Organizations with SQM/SPI perceive software development as more problematic than organizations that have not adopted these approaches. Here, it would be interesting to take a closer look at the individual activities and to analyze the differences in handling the various tasks.

- Most organizations believe that training and education can solve the problems that may arise during the introduction of SQM/SPI. It would be interesting to investigate which particular qualifications management, project leader and staff members need in order to handle SQM/SPI.

- Finally, the study reinforces that SQM/SPI implies organizational development. Therefore, it is an obvious issue to investigate in more detail the influence of SQM/SPI on an organization, in particular on its business processes.

The study indicates that an increased research effort is needed in the areas of software quality management and software process improvement. However, there is first and foremost a need for the dissemination of information - and education - about SQM and/or SPI. Most of the organizations without SQM and/or SPI do not know which standards and methodologies exist. Without such knowledge, it is difficult for them to start software quality management and software process improvement.

\section{Acknowledgements}

We gratefully acknowledge the financial support we have received from the Center for Information Technology (Center for Software Process Improvement) Denmark and the Danish Computer Technology Forum.

\section{References}

[1] Computer World Denmark (1999), Vol. 19, No. 82 \& 88, December 1999.

[2] Zahran, S. (1997). Software Process Improvement Practical Guidelines for Business Success. Addison Wesley Longman, Harlow, UK.

[3] Thomsen, H.E., P. Mayhew (1998). Approaches to Software Process Improvement. In Software Process Improvement and Practice, Vol. 3, Issue 1, pp. 3-17.

[4] Jonassen Hass, A. M., et al. (1997), Bootstrap - the real way to SPI, Quality Week Europe 1997, quoted from Center for Software Process Improvement (2000), Delta report D- 263, pp. 17- 34, Hørsholm, Denmark.

[5] Center for Software Process Improvement, 1998, Danish Experiences with the Improvement of the Software Process, (in Danish). DELTA report D-262, Hørsholm, Denmark.

[6] ISO9001 (1987). Quality Systems - Model for quality assurance in design, development, production, installation and servicing. European Standard EN29001, Brussels, Belgium. 
[7] TickIT (1992). A guide to software quality management system construction and certification using EN29001, Issue 2.0. UK Department of Trade and Industry, London, UK.

[8] Humphrey, W. S. (1989). Managing the Software Process. Addison-Wesley, Reading, USA.

[9] Kuvaja, P., et al. (1994). Software Process Assessment \& Improvement - The Bootstrap Approach. Blackwell, Oxford, UK.

[10] El Eman, K. et. al. (1997). SPICE - The Theory and Practice of Software Process Improvement and Capability Determination. IEEE Computer Society, Los Alamitos, Ca., USA.

[11] Basili, V. R., H.-D. Rombach (1988). The TAME Project: Towards Improvement - Oriented Software Environments. In IEEE Transaction of Software Engineering, Vol. 14, No. 6, pp. 758-773.

[12] Pulford, K. et al. (1996). A quantitative approach to Software Measurement - The Handbook. AddisonWesley, Reading, USA.

[13] Andersen, E. B (1991), Statistics for civil engineers, (in Danish). Akademisk Forlag, Copenhagen, Denmark

[14] Andersen, I. (ed.) (1990) Choosing methods for organizational Sociology, (in Danish). Samfundslitteratur, Copenhagen, Denmark.

[15] Larsen, E. Å., K. Kautz (1997). Quality Assurance and Software Process Improvement in Norway. In Software Process - Improvement and Practice, Vol. 3, pp.71-86, 1997.

[16] European Observatory on Software Engineering (1995). Final Report, PAC France/Germany.

[17] Wang, Y. (1998). Analysis report of the Swedish Benchmarking Survey of Software Development Practices. IVF, Technical Report, Mölndal, Sweden.

[18] Paulk, M. C. et al. (1991). Capability Maturity Model for Software. Technical Report CMU/SEI91-TR24. CMU/SEI Pittsburgh, Pen., USA.

[19] Lee, M. S. Dutta, L. v. Wassenhove (1999). A Empirical Analysis of Software Production Problems in European Software Units. In Pries-Heje, J. et al. (eds.), Proceedings of the 7th European Conference on Information Systems, Vol. II, pp. 465-481, Copenhagen Business School, Denmark.

[20] Herbsleb, J. et al. (1994). Benefits from CMM-based Software Process Improvement: Initial Results. Technical Report CMU/SEI-94-TR13, ESC, R-94013. CMU/SEI Pittsburgh, Pen., USA.

[21] Kautz, K. et al. (2000). Applying a Software Process Improvement Model in Practice: The Use of the IDEAL Model in a Small Software Enterprise. In Proceedings of the International Conference of Software Engineering, 4-11, June, 2000, Limerick, Ireland
[22] Brodman, J. D., D. L. Johnson (1994). What Small Businesses and Small Organizations say about the CMM. In Proceedings of the $16^{\text {th }}$ International Conference on Software Engineering, IEEE Computer Society, pp. 331-340, May 1994.

[23] Brodman, J. D., D. L. Johnson (1997). Tailoring the CMM for small businesses, small organizations and small projects. In Software Process Newsletter, IEEE Computer Society, No. 8, Winter 1997.

[24] K. Kautz (1998). Software Process Improvement in Very Small Enterprises? Does it pay off? In Journal of Software Process - Improvement and Practice, Special Issue on Organizational Change through Software Process Improvement, Vol. 4, No.4, pp. 209-226.

[25] Paulk, M. C. (1999). Using the Software CMM in Small Organizations. Technical Report CMU/SEI99. CMU/SEI Pittsburgh, Pen., USA.

[26] Rogers E. M. (1983). Diffusion of Innovations, Third Edition. The Free Press, New York.

[27] Oakland, J. S. (1993). Total Quality Management ( $2^{\text {nd }}$ edition). Butterworth-Heinemann, Oxford, UK.

[28] Fenton, N. E.., Pfleeger, S. L. (1997). Software Metrics - A Rigorous and Practical Approach, PWS Publishing Company.

[29] Pfleeger, S. L. et al (1997). Status Report on Software Measurement. In IEEE Software, pp. 3343, March/April 1997.

[30] Kautz, K. (1999). Making Sense of Measurements for Small Organizations. In IEEE Software, Vol. 16, No. 2, pp. 14-20.

[31] Iversen, J. H. , Mathiassen, L. (2000). Lessons from Implementing a Software Metrics Program. In Proceedings of HICSS 33, Wailea, Maui, Hawaii.

[32] Bang, S. et al. (1991), Quality Management in Systems Development, (in Danish). Teknisk Forlag, Copenhagen, Denmark.

[33] Borum, F. (1995). Strategies for Organizational Change (in Danish). CBS Publishing Company. Copenhagen, Denmark.

[34] Andersen, N. E., et al. (1990). Professional Systems Development - Experience, Ideas, Action. Prentice Hall, Hemel Hempstead, UK. 